\section{Toward long-term health among people with HIV}

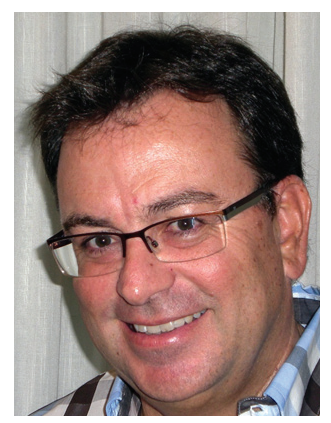

Antonio Antela* speaks to Daphne Boulicault, Commissioning Editor: Antonio Antela obtained his medical degree in 1983 followed by a specialty degree in internal medicine in 1989, both at the University of Santiago de Compostela (Spain). Between 1989 and 1991, he was a research fellow in infectious diseases at the Ramón y Cajal Hospital, in Madrid, Spain. In 1991, he worked as an attending physician in the HIV Unit of the Infectious Disease Department at the same institution, responsible for the management and follow-up of over 1500 HIVinfected patients. He subsequently obtained a PhD degree in 1999. He worked in the AIDS Program of the Pan American Health Organization (PAHO), in Washington, DC, USA, in 2003, and in the Fundación VIHDA AIDS Clinic in Maragua (Kenya), in 2004. In 2006, he joined the HIV and Infectious Diseases Department of the University Hospital of Santiago de Compostela, where he still carries out his clinical and research work in the infectious diseases and HIV fields.

First draft submitted: 3 December 2015; Accepted for publication:

21 December 2015; Published online: 3 February 2016

Q What inspired you to work in the field of HIV?

After I finished my specialty training in internal medicine, I got a fellow position in infectious diseases, in Ramón y Cajal Hospital, in Madrid (Spain). I began work there in 1990, at a time when AIDS was absolutely out of control in Spain, particularly in the bigger cities. The wards were full with admissions due to opportunistic infections and tumors, and also clinical manifestations of drug abuse, the main source of HIV infection acquisition in Spain, in the first wave of the epidemic. My patients were very ill, and with social problems including isolation. Although we had little to do for them regarding HIV infection, other than treating opportunistic manifestations and other clinical issues, the mix of scientific challenge and social work seemed to me the essence of medicine, and thus I found my calling in HIV.

Q Have any colleagues, past or present, particularly influenced you?

Absolutely. My teacher, Dr Luis Buzón (Ramón y Cajal Hospital, Spain), not only instructed me in all aspects of HIV infection at that time but also, perhaps more importantly, instructed me on how to care for patients in a comprehensive and global way. Alongside the medical problems, it is essential to concern ourselves with social integration, the elimination of stigma, providing support for drug rehabilitation and being a friend. Of course, there are many other colleagues, nationally and internationally, from whom I have learned a lot but the biggest inspiration and the reason for my dedication

*Infectious Diseases Department, Hospital Clínico Universitario Santiago de Compostela, Spain; antonioantela@mundo-r.com

\section{KEYWORDS}

- comorbidities • HIV • long-term 
to HIV undoubtedly came from Dr Buzón, who unfortunately had to leave the field after his high workload left him burnt out.

Q What would you describe as the greatest advances in HIV care over the course of your career?

It is difficult to pinpoint one. I would say that the first big achievement occurred in 1996, with the advent of HAART, when progression to AIDS and mortality due to HIV infection dropped dramatically. At the same time, we were able to prevent mother-to-child HIV transmission, allowing $\left.\operatorname{HIV}^{+}\right)$women to have families. Later, in 2006, when several drugs of new drug classes were released at the same time, we could finally help all those patients who were struggling with suboptimal therapies due to previous virologic failures and accumulation of resistance. Finally, the use of single tablet regimens has made therapy more convenient and more easily included into the patient's life, allowing them to have a normal life in all aspects.

\section{Q You recently contributed to a publication} entitled 'Going beyond undetectable: a review of the unmet long-term health needs of people living with HIV'. Can you explain the need for such a document?

Fortunately, we live at a time in which we have enough good, efficient and safe drugs to ensure that nearly $100 \%$ of HIV patients have maintained virologic suppression (at least in those places where there is free and universal access to antiretroviral therapy). As a consequence, our patients are living longer and have begun to experience the clinical consequences of aging such as hypertension, cardiovascular disease, kidney dysfunction, liver insufficiency, osteoporosis or neurocognitive impairment. Therefore, we must change our way of caring for patients, focusing not only on controlling HIV infection itself but on detecting and managing all these comorbidities, probably in a multidisciplinary fashion. This document tries to set the basis of such a new approach [1].

\section{Q What were some of the main outcomes of this publication?}

To explain the need for a change in the approach to caring for patients with HIV and to set the basis of such an approach, focusing more on comorbidities and using a multidisciplinary methods.
How can we improve the detection of comorbidities among people living with HIV? We have to anticipate the main comorbidities, as I mentioned previously. There are some updated international guidelines such as the latest European AIDS Clinical Society guidelines [2], which set out the main procedures and the period in which to perform them. This diagnosis can be made from the HIV clinic by HIV physicians, though long-term management is probably best handled by other specialists. That is why we should establish, each in its own setting, as multidisciplinary a team as possible.

\section{Q The publication focused on those living} in developed countries, but what are some of the main challenges facing people with HIV who live in developing countries?

First of all, we have to try to achieve the last challenge from UNAIDS, the WHO agency for the fight against AIDS. This last challenge, called 90-90-90, states that we should have diagnosed $90 \%$ of people living with HIV, of those, $90 \%$ should be receiving therapy, and of those, $90 \%$ should have undetectable viral load. We are still far from achieving these goals, not only in developing countries, but also in the developed world. Once we improve access to care and therapy, which to be honest have improved a lot over the last 15 years in developing countries, we can start to worry about the consequences of aging and comorbidities in these populations.

\section{Q Do any treatments, recent or forthcoming,} have you particularly excited?

I think integrase inhibitors are a real revolution in HIV therapy. They are not only the drugs with the highest efficacy, but also with the best safety, convenience and drug-drug interactions and metabolic profiles. For all these reasons, they are already the reference in HIV therapy and will be more so in the coming years. Some of the new integrase inhibitors will be able to be administered for very long periods of time, perhaps 1-3 months, which will improve adherence and outcomes in some particular settings and clinical scenarios, like pre-exposure prophylaxis, contributing to limit the epidemic and to finally control it.

\section{Q How do you see your field progressing over the next 5-10 years?}

We have to enhance early diagnosis to reduce the number of people living with unknown HIV 
infection, limit transmission and help to control the epidemic. We also have to administer therapy to all people from diagnosis, thereby reducing morbidity and mortality in diagnosed people as well as the community viral load, further contributing to ending the epidemic. Drugs will probably become even more efficient and safer than today, mostly based on integrase inhibitor based combinations, although new drug classes will appear (maturation inhibitors, attachment inhibitors, gene therapy, etc). The eradication of HIV will be closer to reality than ever and it is likely that significant advances will be made on the vaccines front, both preventive and therapeutic. Finally, it is mandatory that all these advances will be implemented also in developing countries, so that we can achieve a world free of AIDS.

\section{Disclaimer}

The opinions expressed in this interview are those of the interviewees and do not necessarily reflect the views of Future Medicine, Ltd.

\section{Financial \& competing interests disclosure}

The author has no relevant affliations or financial involvement with any organization or entity with a financial interest in or financial conflict with the subject matter or materials discussed in the manuscript. This includes employment, consultancies, honoraria, stock ownership or options, expert testimony, grants or patents received or pending, or royalties.

No writing assistance was utilized in the production of this manuscript.

\section{References}

1 Key Opinions in Medicine. http://keyopinions.info

2 European AIDS Clinical Society. EACS

Guidelines 8.0.

www.eacsociety.org 